\title{
Management and Leadership: A Case Study
}

\author{
Diana El Rabih \\ Monty Holding, Beirut, Lebanon
}

\begin{abstract}
In this paper, we show the difference between management and leadership through a case study, by presenting a management situation in a company and by studying the facts in this situation, the events in this situation, the analysis of these facts and events, and the learned lessons from this case study. We analyze in this case study the managerial situation especially for a manager $\mathrm{X}$ in our case study, who had some flaws in his style of management leaking of leadership. We learn some general and specific lessons in relation to our studied managerial situation. Our analysis proposes multiple improvements of this managerial situation especially for the manager $\mathrm{X}$ by combining his management skills with his leadership skills. We show through this case study the main differences between the management and the leadership. Also, we illustrate in this paper the interest to combine leadership skills with management skills for the manager $\mathrm{X}$ in our studied managerial situation and to adapt the management styles for the manager $\mathrm{X}$ according to the managerial situation.
\end{abstract}

Keywords: leadership, leadership styles, management

\section{Introduction}

In this paper, we will provide a description of a managerial situation in a company in terms of facts and events, and then, we will conduct an analysis of this situation by using the concepts of leadership and management. Also, we will describe the lessons learned through this experience those we aim to apply. Our following analysis proposes multiple improvements of this managerial situation especially for the manager $\mathrm{X}$ by combining his management skills with his leadership skills. We show through this case study the main differences between the management and the leadership.

Leadership is prior to management; it is defined as the ability to influence. The leadership is accessible to all. Ideally, the leader is one who, from all sources influence, favors learning from others of the quality of its own conduct. And thanks to the identification of its own behavior on the part of others, he managed to maximize its influence, that is to say, to ask little to get what he wants. It is through behavior that a manager can access to leadership.

Leadership is the ability to guide, direct, orient, decide, and synthesize if necessary, to communicate, decide. Leading does not mean to show outrageous power. The leader has enough personal dimensions to step back, a distance that ensures its lucidity. He must be aware of its power, knowing the needs and the limits that are personal to him.

Diana El Rabih, Master Degree \& Engineering Degree, R\&D Executive, Research and Development Department, Monty Holding, Beirut, Lebanon. 
The manager can develop, encourage, allow everyone to express themselves, to be proactive, to integrate the objectives, and give permission to develop and optimize skills. The manager of the team fixes goals. He will guide his employees towards these goals. He has knowledge, but not all knowledge.

In fact, there is an essential difference between leadership and management which is captured: Leadership is setting a new direction or vision for a group that they follow: A leader is the spearhead for that new direction. Leadership is about aligning people to the vision that means buy-in and communication, motivation, and inspiration. Management controls or directs people/resources in a group according to principles or values that have been established. Management is a set of processes that keep an organization functioning. The processes are about planning, budgeting, staffing, clarifying jobs, measuring performance, and problem-solving when results did not go to plan.

The difference between leadership and management can be illustrated by considering instances when there is one without the other. Leadership without management sets a direction or vision that others follow, without considering how the new direction is going to be achieved. Management without leadership controls resources to maintain the status quo or ensure things to happen according to already-established plans. However, a referee does not usually provide "leadership" because there is no new change, no new direction. There are many different types of leadership (or management) style. Different situations, groups, or cultures may require the use of different styles in order to set a direction or ensure that it is followed.

\section{Facts and Events}

In a company. we have a team of engineers, where $\mathrm{X}$ was the team manager and $\mathrm{Y}$ was the director of the team. There was no project leader on this team but engineers orchestrating their development work by providing specifications and within realization.

This manager $\mathrm{X}$ was not specialized in the technical aspect; he had no technical experience in the job. He was not one who met all the technical issues. Y, the director of the team had the mastery of the technical aspects of the work and great technical experience. So, it is $\mathrm{Y}$ that meets the technical issues instead of $\mathrm{X}$ and in this case there was no technical leader in the team.

$\mathrm{X}$ was the manager of the team of engineers, so it made sense to manage the work of this team engineers, set up goals, and ensure they are completed. In addition, $\mathrm{X}$ serves as the interface with the director of the engineering team that was at the same time technical leader of this team.

We noticed that the manager uses $\mathrm{X}$ exaggerated directive style as a way to manage the team activities and it does not take into account the competences and the autonomy of the team members or their professional maturity. It adopts very directive style (autocratic style) and oriented undirected people productivity. In addition, the manager $\mathrm{X}$ does not adapt its management style with this team according to the managerial situation.

\section{Analysis and Interpretation}

The logical, analytical capacity, and strategic vision are important qualities for a manager. Obviously, a manager must know how to organize and reflect. Also, emotional qualities are important to be a human manager. A manager is above all a human being who lives, embodies what he thinks, what he says. 


\section{The Observed Dysfunctions}

From our observations of this managerial situation, we find that many times with team members, the manager $\mathrm{X}$ is afraid to lose its place. This fear leads to excessive exercise of power. The author thinks it is better for the manager to have $\mathrm{X}$ reporting, to control things differently. If he uses this reporting to sharing purposes, exchange, and then it will foster collective learning and team cohesion.

\section{The Management Concerned With Productivity and People}

The manager $\mathrm{X}$ adopts a management style affected only by productivity. This will have long-term negative consequences for his team. The effectiveness of this management style adopted is the result of an environment human intervenes at least in the work. Hence, the suggestion for the manager $\mathrm{X}$ to adopt a management style concerned by people as well as by productivity: a management style in which the performance of work resulting from the involvement of employees and interdependence leads them to converge to a common issue, or a balanced management style in which adequate performance is obtained through a balance between the need for performers while maintaining the moral of the people at a satisfactory level.

\section{The Balance of Management for a Successful Team}

The manager $\mathrm{X}$ does not adopt a balanced management between productivity and people, and he has not an effective strategy for long-term team. Indeed, in figure 1, leadership is represented by a bicycle that must be balanced to move forward and have a successful team. In figure 1, we see that the leadership is based on a strategy, a vision, and a mission in order to achieve goals and meet expectations. It can be oriented to customers (more concentration on productivity) or oriented to people (more concentration on team members) or can be a compromise of these two approaches (and it will be balanced).

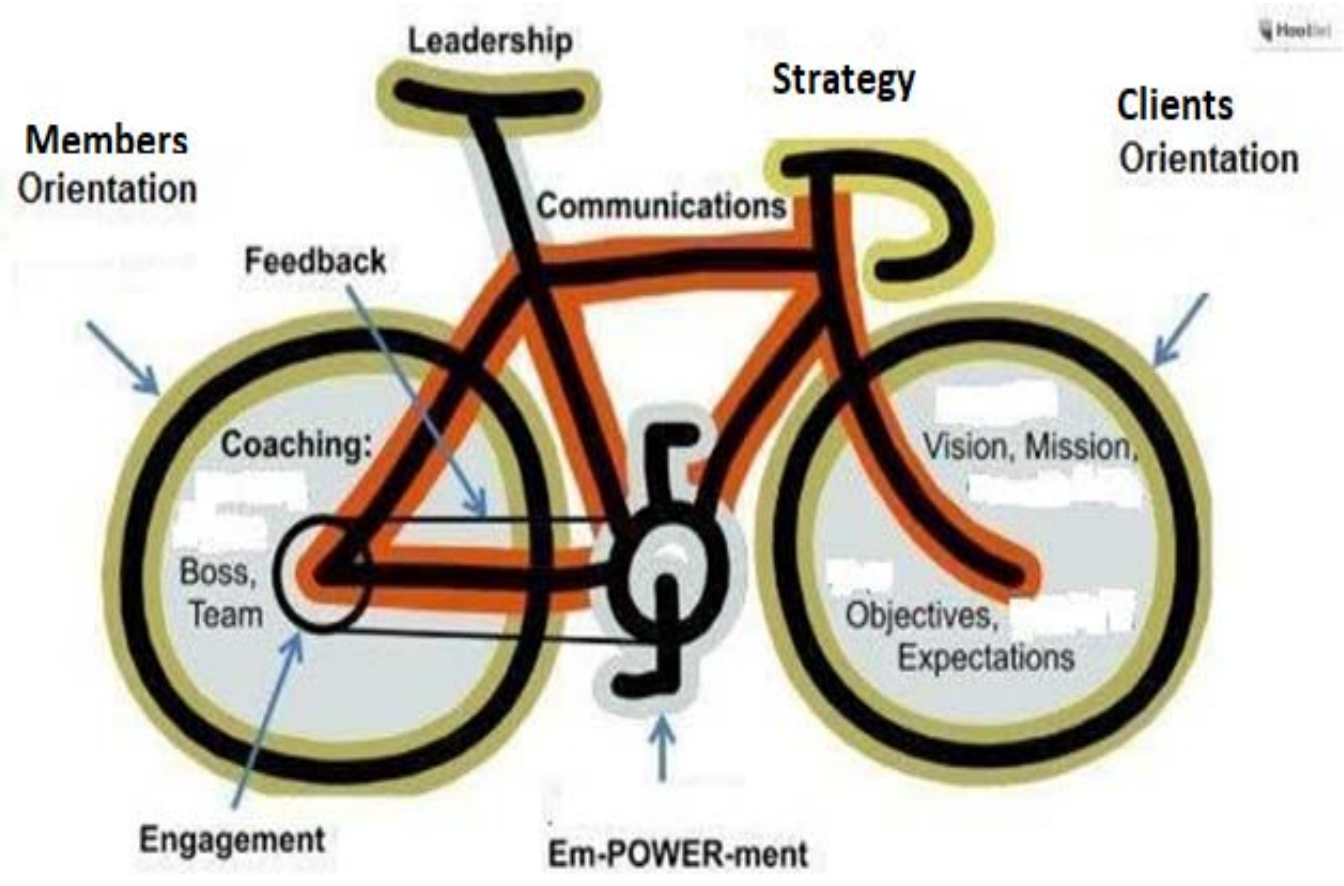

Figure 1. Balance of Management.

The main elements of leadership are the boss and team members, communication between them and their 
customers, and return (feedback) of their clients or team members.

\section{Adaptation of Management Depending on the Situation: Situational Management}

The manager $\mathrm{X}$ does not change his style according to the situation and the skills of his team member or their degree of autonomy. Indeed, every manager has a predominant management style. The predominant style is not effective in all contexts. The situational management aims to identify levels of employee development to adapt its management style. It therefore takes account both people and situations to make the most of the energy expended and maximize the result of the team members.

The directive management style aims that those employees will be effective. He is more particularly directed towards the task at hand.

The persuasive management style explains a lot. He argues, and is trying to convince. It unites, encourages, supports, and promotes.

The participative management style aims that those employees will be stakeholders. It mobilizes, implies, and proofs to be open.

The delegate management style is less present; it trusts the employees. It shows the tasks and results to be achieved and leaves the employees implement their own action plans and their own methods.

In the following figure shows that each management style S (i) corresponds to a degree autonomy A (i) at a level of competence (level of maturity).

\section{MOTIVATION}

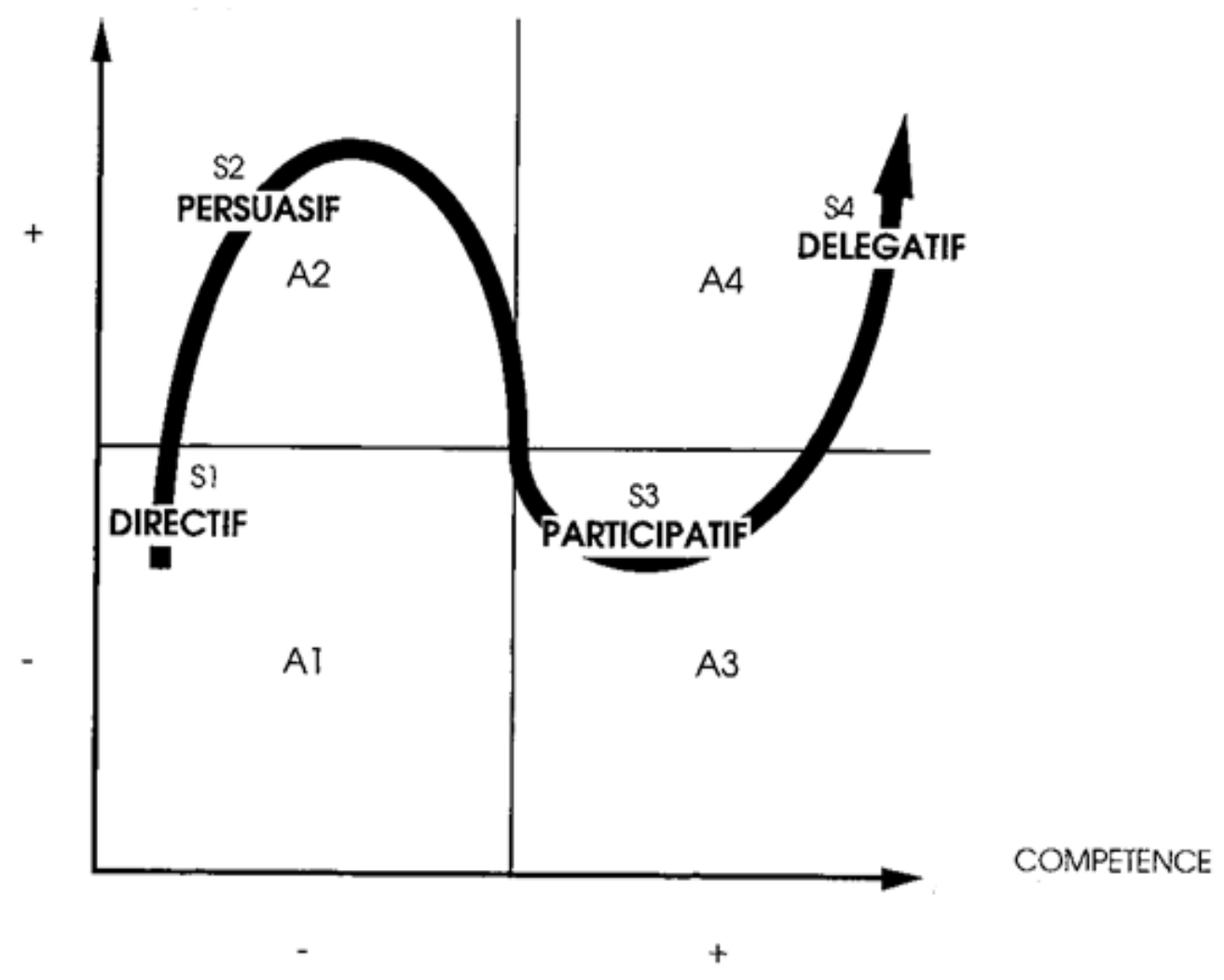

Figure 2. Management Styles. 


\section{Appropriate Situations for Each Management Style}

For the directive style: If there is an emergency, if the issue is important, if there is need to structure, whether employees are not autonomous.

For the persuasive style: To encourage a fragile employee, to explain well the reason of a decision, and to motivate employees.

For the participative style: To propose to solve all the problems not decisions, to listen very different proposals, and for negotiating an action plan.

For delegate style: If the manager is sure of the quality of autonomy of its employees, if the means and the information to a good result are given.

\section{Unsuitable Conditions for Each Management Style}

For the directive style: If the manager minimizes the autonomy of a collaborator.

For the persuasive style: If the manager hides the truth by good words, if the manager infantilizes its employees.

For the participative style: If the manager let his staff find solutions while he has already made the decision, if the manager does not distinguish negotiable non-negotiable, if the manager will call on his collaborators on points without interest.

For delegate style: If the manager flees his responsibilities if the manager does not assume the consequences of his delegation.

\section{Learned Lessons}

Based on our readings on leadership and several managerial situations we experienced, we were able to draw the following lessons, which can serve as guide. We begin with the general lessons and then we turn to coach related managerial situation described above.

\section{Combining Leadership and Management Skills}

The manager should combine his management skills with leadership skills according to the situation with his team members.

\section{Make Decisions}

Good managers make good decisions.

\section{Anticipate the Consequences of His Actions}

Before taking a decision, the manager should evaluate all possible consequences according to the "dynamic systems”.

\section{Agree to Hear the Bad News}

The manager should be immediately informed of the bad news that arrange not with time. There is no point hiding things.

\section{Do Not Decide in the Heat of the Moment}

It is better to leave a period of reflection to do not react to his emotions. 


\section{Take Responsibility}

Take full responsibility for what is happening or has happened. If a team member does not understand his instructions, the team manager cannot blame him. It is his role of leader to ensure that the team members understand their instructions.

\section{Pay Attention to His Ego}

The manager must pay attention to his ego.

\section{Keeping Things Simple}

Complexity is the enemy of performance.

Private lessons related to the managerial situation described above:

Adapting management to the situation or team members. Performing situational management by adapting management style according to the situation or depending on the maturity and autonomy of team members.

Balancing management style. Making balanced management between productivity and people will be better at the long term and makes the most successful team.

Do not fear losing his place. Do not be afraid of losing his place for not making the excess power. Delegate or report if necessary.

\section{Conclusions and Recommendations}

We described in this paper the facts observed by us in this managerial position. Then, we analyzed the situation managerial especially for the manager $\mathrm{X}$ who had some flaws in his style of management leaking of leadership. We then learned lessons general and specific in relation to our studied managerial situation. Our analysis in this paper proposes multiple improvements of this managerial situation especially for the manager $\mathrm{X}$ by combining his management skills with his leadership skills. We show in this paper through this case study the main differences between the management and the leadership, which are captured in our case study as follow: Leadership is setting a new direction or vision for a group that they follow. A leader is the spearhead for that new direction. Leadership is about aligning people to the vision that means buy-in and communication, motivation and inspiration. Management controls or directs people/resources in a group according to principles or values that have been established. Finally, we illustrate in this paper the interest to combine leadership skills with management skills for the manager $\mathrm{X}$ in our studied managerial situation and to adapt the management and leadership styles for the manager $\mathrm{X}$ according to the managerial situation.

\section{References}

Hamdan, Z. (2017). Courses of management and leadership. Courses of Superior Institute of Applied Economics.

O’Reilly, C. A., Caldwell, D. F., \& Chatman, J. A. (2005). How leadership matters: The effects of leadership alignment on strategic execution. Working Paper No. 1895.

Rodrigo, R (2012). Leadership and management essay. The Write Pass Journal.

Santori, G. (2015). Management and leadership paper. Management 330, MGT 330.

The Institute of Leadership and Management. (2018). White Papers. 